\title{
Sotos sendromu: Bir vaka sunumu
}

\author{
Güler Burcu Senirkentli(0000-0003-4918-5504) ${ }^{\alpha}$, Resmiye Ebru Tirali(0000-0001-6487-3984) ${ }^{\alpha}$, \\ Didem Sakaryalı(0000-0001-7850-2375) $)^{\alpha}$
}

Selcuk Dent J, 2020; 7: 95-98 (Doi: 10.15311/selcukdentj.510518)
Başvuru Tarihi: 09 Ocak 2019 Yayına Kabul Tarihi: 27 Şubat 2019

\begin{abstract}
Öz
Sotos sendromu: Bir vaka sunumu

Sotos sendromu, çocukluk döneminde endokrin bir bozukluk olmaksızın, aşırı büyüme, makrosefali, kendine özgü yüz görünümü ve çeşitli derecelerde öğrenme güçlüğü ile karakterize genetik bir durumdur. Olguların çoğu sporadik olup, otozomal dominant kalıtım modeline uyan aileler bildirilmiştir. Sendromdan esas sorumlu olan gen nükleer reseptör bağlayıcı SET domain1 (NSD1) proteinini kodlar. Nadir görülen bu sendrom ilk olarak 1964 yılında, ılımlı mental retardasyonu bulunan beş vakada Sotos ve arkadaşları tarafından tanımlanmıştır. Yüksek alın saç çizgisi, makrosefali, frontal bossing, uzun ve ince yüz görünümü, fronto-temporal bölgede saç seyrekliği, aşağı çekik palpebral fissürler ve belirgin mandibula karakteristik yüz görünümünü oluşturur ve ileri kemik yaşı ve değişik derecelerde mental gerilik diğer tanı kriterleridir. Bu olgu sunumunda yaygın diş çürüğü ve spesifik oral bulguları bulunan 6 yaşındaki Sotos sendromlu vakanın dental açıdan yönetimi vurgulanmıştır.
\end{abstract}

\section{ANAHTAR KELIMELER}

Hızlı büyüme, mental retardasyon, Sotos sendromu

Sotos sendromu, ilk olarak 1964 yılında, aşırı boy uzunluğu, akromegalik gö̈ünüm, hafif mental retardasyonu olan bes, vakada Sotos ve arkadașları tarafından tanımlanmıștır. ${ }^{1}$ Sotos sendromu ayırt edici bir yüz görünümü; öğrenme yetersizliği ve aşırı büyüme ile karakterizedir. Bu üç klinik özellik, Sotos sendromunun temel özellikleri olarak kabul

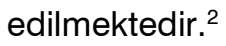

Sotos sendromunda yüz görünümündeki spesifik özellikler, geniş ve belirgin alın, frontotemporal bölgede saç seyrekliği, aşağı eğimli palpebral fissürler, malar bölgede kızarıklık, uzun ve dar yüz ve uzun çenedir. Sendromun diğer tipik bulguları ise davranış bozukluğu, ileri kemik yaşı, kardiyak, kranial, renal anomaliler, skolyoz, hipertelorizm veya telekantus, kemerli burun, belirgin mandibula gibi fasiyal bulgular ile serebellar nistagmus ve strabismustur. ${ }^{2,3,4} \mathrm{Bu}$ güne kadar yaklasılk 400 vaka bildirilmiștir. Hastalığın prevalansı bilinmemekle birlikte yaklasılk 1/10000 ile 1/50000 arasında olduğu

\begin{abstract}
Sotos syndrome: A case report

Sotos syndrome is a genetic condition characterized by excessive growth, macrocephaly, specific facial appearance, and varying degrees of learning disability without an endocrine disorder in childhood. Most of the cases were sporadic and the families who matched the autosomal dominant inheritance pattern were reported. The gene responsible for the syndrome encodes the nuclear receptor binding SET domain1 (NSD1) protocol. This rare genetic syndrome was first described by Sotos et al. in 1964 in five cases with excessive height, acromegalic appearance and moderate mental retardation. The high forehead hairline, macrocephaly, frontal bossing, long and thin facial appearance, hair sparse in the fronto- temporal region, downward slanting palpebral fissures and prominent mandible are the characteristic facial appearance, and the advanced bone age and mental retardation in different levels are the other diagnostic criteria. The aim of this case report is to emphasize the dental management of 6 -year-old Sotos syndrome with common dental caries and specific oral findings.
\end{abstract}

\section{KEYWORDS}

Rapid growth, mental retardation, Sotos syndrome

\section{tahmin edilmektedir. ${ }^{4}$}

Sendromun oral bulguları arasında hipodonti, mine hipoplazileri, tolon tüberkülleri, füzyon, geniş pulpa odaları, maksilla ve mandibulada diş eti çekilmesi, yüksek damak, dişlerde erozyon gözlenmektedir. ${ }^{5}$

Literatürde otozomal dominant kalıımın etkili olduğunu düşündüren, birbirini takip eden altı jenerasyonda benzer bulgular saptanan bir aile bildirilmiş olmasına karşın vakaların çoğu sporadiktir. ${ }^{6}$ Sotos sendromu ile ilişkili olduğu bilinen tek gen olan NSD1, 2002 yılında klonlanmış olup olguların çoğunda mutasyonlar gösterilmiştir. ${ }^{7,8}$ NSD1 anormalliklerinin, Sotos sendromu için yüksek özgüllük ve duyarlılığa sahip olduğu bildirilmiştir. ${ }^{2,9}$

Sotos sendromunun ayırıcı tanısı Weaver sendromu, Beckwith-Wiedemann sendromu, Simpson-GolabiBehmel sendromu, Bannayan-Riley-Ruvalcaba sendromu gibi diğer aşırı büyüme gözlenen sendromlarla yapılmaktadır. ${ }^{10}$ Sotos sendromu olan kişiler öğrenme güçlüğü, konuşma gecikmeleri, davranış problemleri, 
kalp, böbrek anomalileri, skolyoz, nöbet yönetimi için uygun uzmanlara yönlendirilir. ${ }^{10}$

Kliniğimize yaygın diş çürüğü ve diş ağrısı nedeniyle başvuran ve daha önce Sotos sendromu tanısı konmuş vaka, Sotos sendromunun oral ve maksillofasiyal bulguları değerlendirmek amacıyla sunulmuştur.

\section{OLGU SUNUMU}

Daha önce Sotos sendromu tanısı konan, 6 yıl 7 aylık hasta kliniğimize dental ağrı ile başvurmuştur. Hastadan alınan ayrıntılı medikal hikayesinde eşlik eden herhangi bir sistemik hastalık olmadığı ancak ilgili bölümlerde kontrol altında olduğu, aile hikayesinde Sotos sendromlu başka birey olmadığı öğrenilmiştir. Klinik muayenesinde sendroma ait diğer bulgular arasında sayılan dismorfik yüz görünümü yanında (Resim 1), makrosefali, geniş açık alın, belirgin çene yapısı ve hipertelorizm bulguları gözlenmiştir. Dental muayenesi yapıldığında karma dentisyonda olduğu görülmüştür. Yaygın diş çürüklerinin yanında yetersiz oral hijyen, marjinal gingivitis ve derin damak kubbesi gözlenmiştir (Resim 2). Radyografik inceleme sonucunda yaygın diş çürüklerinin yanında literatürden farklı olarak, bilateral olarak izlenilen çift köklü ve çift kanallı mandibularmaksiller kanin dişleri gözlenmiştir (Resim 2).

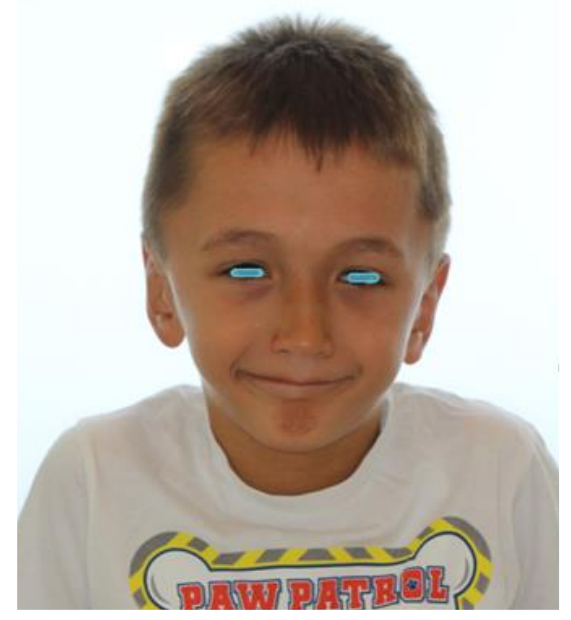

Resim 1.

Dismorfik yüz görünümü

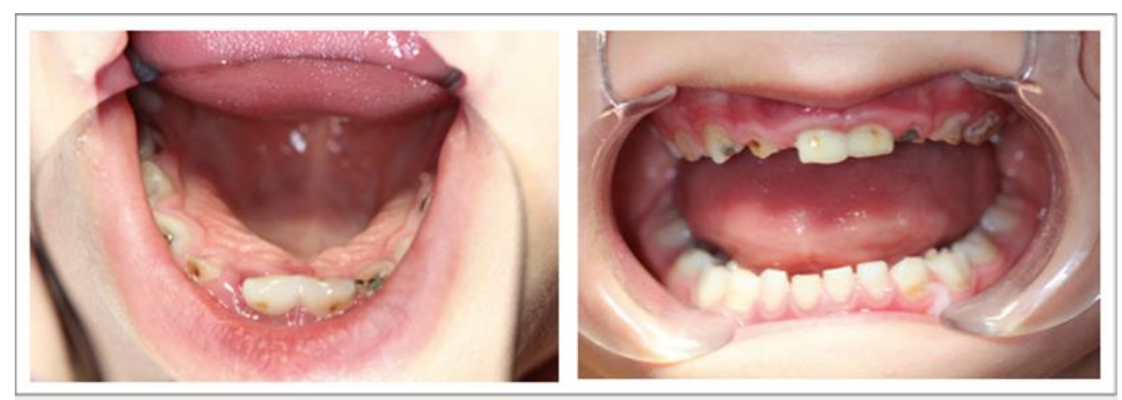

Resim 2.

Dental tedavi öncesi ağız içi fotoğraf

Hastanın kooperasyonu kapsamlı bir dental tedavi için uygun olmadığından, işlemleri genel anestezi altında tamamlanmış; 55, 54, $53,63,75,74,36,46$ numaralı dişlerine restoratif tedavi uygulanmış; 64 , $65,84,85$ numaralı dişlerine ise oral hijyenin kötü olması nedeniyle kanal tedavisi ve restorasyon tercih edilmemiş ve çekim işlemi yapılmıştır. 51 , $52,61,62,71,81$ nolu mobil dişler extübasyon işlemi ve ya sonrasında apire edilme riski bulunduğundan çekimi uygun görülmüştür. Hastanın işlem sonrası 1. hafta ve 1. ayda kontrolleri yapılmıştır (Resim 3, Resim 4). Dental durumu stabil hale gelen hastanın, yer tutucu uygulaması kooperasyon sağlanamadığı için ertelenmiş, veliye sık kontroller ile takip edilmesi ve oral hijyeninin sağlanması konusunda bilgi verilmiştir.

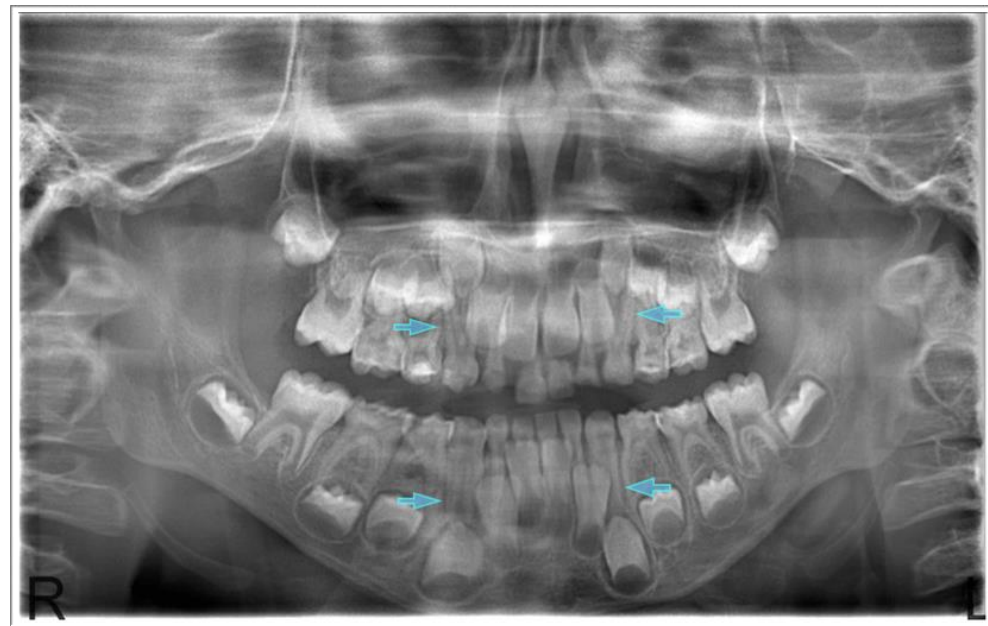

Resim 3.

Distal falanksların osteolizi sonucu tombul el görülmektedir

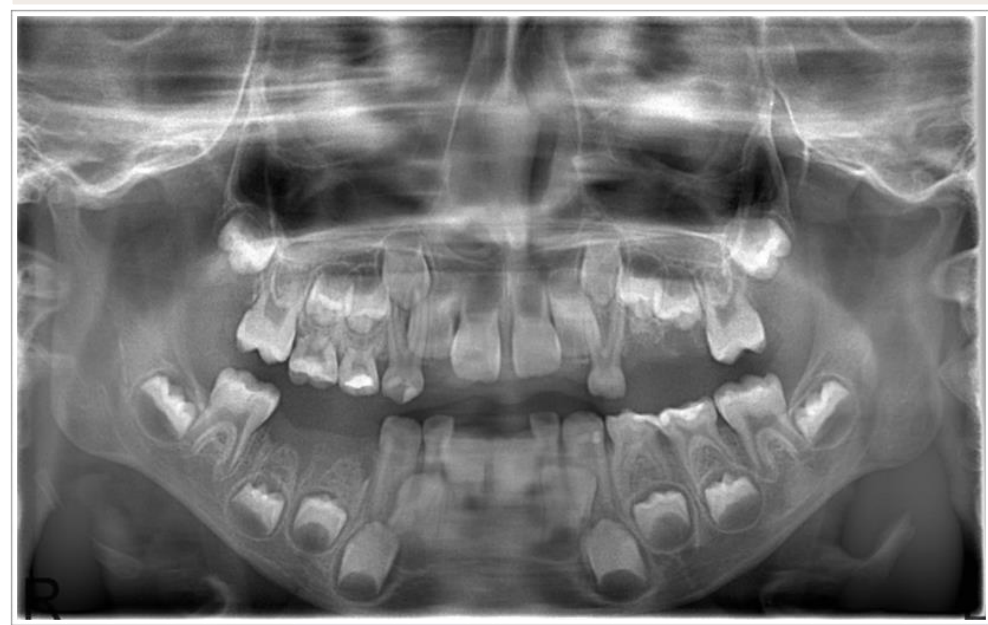

Resim 4.

Dental tedavi sonrası 1. ay panoramik radyograf 

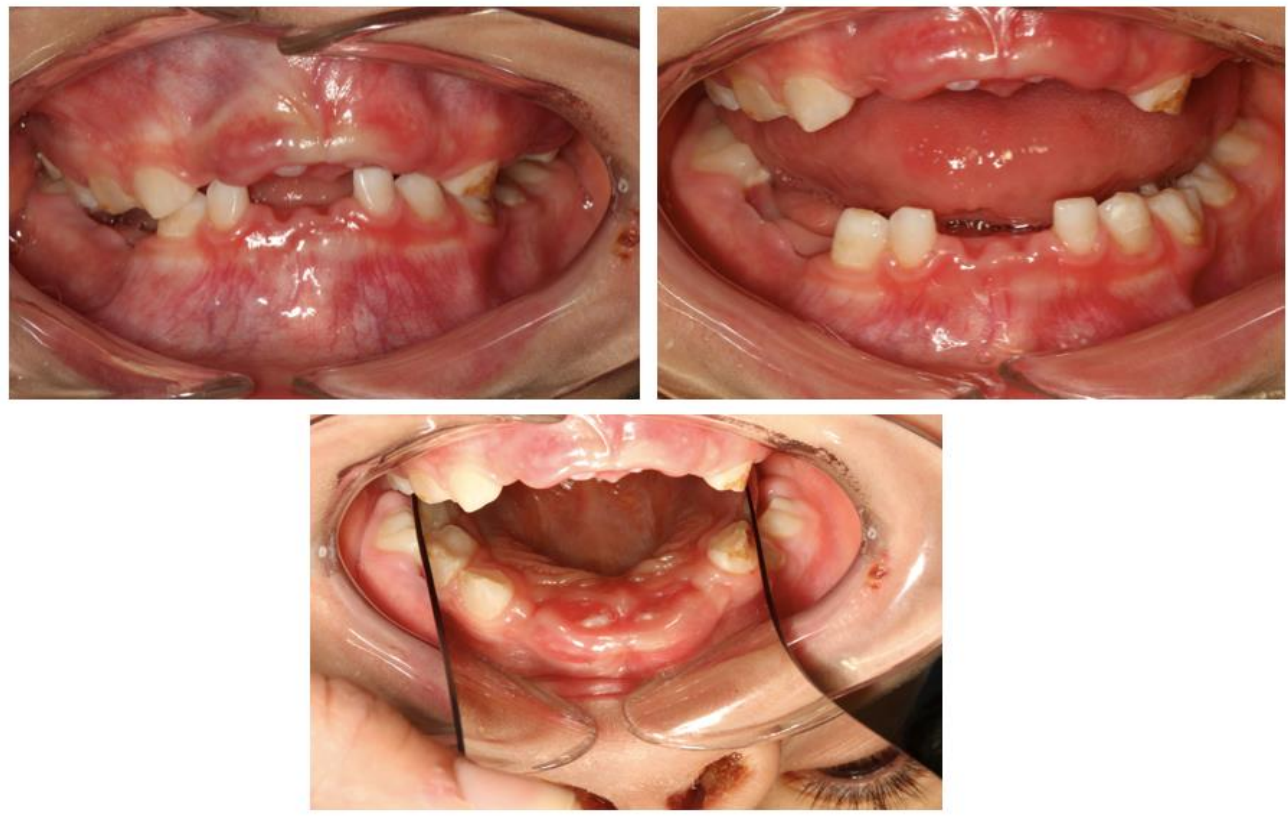

Resim 5.

Dental tedavi sonrası ağız içi görüntüler

\section{TARTIŞMA}

Sotos ve ark. tarafından ilk kez 1964 yılında aşırı boy uzunluğu, akromegalik gö̈ünüm, ılımlı mental retardasyonu bulunan beş olgu ile Sotos sendromu tanımlanmıştır. Sotos sendromunun tipik bulguları olan boy ve baş çevresi persentillerinin büyük olması, dolikosefali, alın çıkıklığı, hiperteleroizm veya telekantus, kemerli burun, düşük düzeyde palpebral fissur, yüksek kubbe damak gibi yüz bulguları,11 olgumuzda gözlemlenmiştir.

Sotos sendromlu vakalarda en sık bildirilen dental semptomlardan bir diğeri de hipodontidir. ${ }^{12}$ Vakamızda hipodonti bulgulanmamakla birlikte Sotos sendromlu bir vakada çift köklü çift kanallı kanin dişlerinin literatürde ilk defa rapor edildiği düşünülmektedir.

Sotos sendromu otozomal dominant kalitsal bir sendromdur. Bireylerin \%95'inden fazlasında de novo patojenik varyant görülmektedir. Etkilenen bireylerin ise gelecek kuşaklara sendromu aktarma olasılığı \%50' dir. Bu açıdan aile bireylerinin bilgilendirmesi ve diğer çocuklarında ve muhtemel gebeliklerde NSD1 geni açısından testler önerilmektedir. ${ }^{2}$

$\mathrm{Bu}$ vakada dental tedavilerin radikal yaklaşımla uygulanması, işlemlerin genel anestezi altında yapılması ve oral hijyenin sağlanmasında güçlük çekilmesi nedeniyle tercih edilmiştir. Dolayısıyla bu vaka kompleks medikal hikayeye sahip hastaların pediatrik dental merkezlere yönlendirilip, koruyucu uygulamalarla takibinin önemini vurgulamaktadır. $\mathrm{Bu}$ şekilde; dişlerin erken kaybı, ağrı, sepsis gibi komplikasyonların yaşanmasının engellenmesi amaçlanmalıdır.
Sotos semdromunda gelişimsel gecikme, motor becerilerde ve konuşmada gecikme, konjenital hipotoni görülebildiği, bu bulgularda yaşla birlikte azalma olabileceği bildirilmiştir. Genelde sakin yapıda olmalarına karşın bazı vakalarda çok şiddetli davranış problemleri gözlenmiştir. ${ }^{13}$ Hastamızın hikayesinde mental gerilik açısından hafif bulgular olduğu görülmüştür.

Yapılan literatür incelemesinde Sotos sendromu tanısı konulan vakalarda artmış neoplazma riski (örn. Wilms tümörü, hepatosellüler karsinom, parotis tümörü, dev hücreli granülom) bildirilmiştir. Dolayısıyla hastanın takip süresince olası neoplazmlara karşı uygulanacak tedavilerde dikkatli olunmalıdır. ${ }^{14}$

Sotos sendromunda NSD1 geninin mutasyonuna bağlı olarak maksiller dişlerin labiale açılanmalarında artış, mandibula gelişiminde gerilik, posterior cross-bite görülmektedir. ${ }^{15}$ Literatüre bakıldığında distraksiyon osteogenezi ile tedavi edilen maxiller ve mandibular hipoplaziye bağı bir retrüzyon vakas ${ }^{16}$ ve süt dişlerinde yaygın hipoplazi bulgulanan bir vaka ${ }^{17}$ ile premolar hipodontisinin gözlendiği bir vaka serisi bildirilmiştir. ${ }^{18} \mathrm{Bu}$ hastalar maloklüzyon, dental sağlık ve eşlik edebilecek oral komplikasyonlar açısından takip edilmelidirler.

\section{SONUC}

Kesin tanısı genetik testlerle konulan bu sendromun tanısında fiziksel ve mental durumun yanında oral bulguların da tanıya yardımcı olacağı düşünülmektedir. Fonksiyonel bir daimi dentisyon için uygun tedavi planı geliştirilmesi ve ailenin sistemik komplikasyonlar hakkında bildirilmesi önem taşımaktadır. 


\section{KAYNAKLAR}

1. Sotos JF, Argente J. Overgrowth disorders associated with tall stature. Adv Pediatr 2008; 55: 213 54.

2. Katrina Tatton-Brown, Trevor RP Cole, Nazneen Rahman. Sotos Syndrome. GeneReviews Seattle (WA): University of Washington, Seattle; 2015; 19932019.

3. Leventopoulos G, Kitsiou-Tzeli S, Kritikos K, et al. Aclinical study of Sotos syndrome patients with review of the literature. Pediatr Neurol 2009; 40: 357-64.

4. Cole TRP, Hughes HE. Sotos syndrome: a study of the diagnostic criteria and natural history. J Med Genet 1994; 31: 20-32.

5. Norimitsu Hirai, Kensuke Matsune, Hirofumi Ohashi. Craniofacial and Oral Features of Sotos Syndrome: Differences in Patients With Submicroscopic Deletion and Mutation of NSD1 Gene. Am J Med Genet Part A 2011; 155: 2933-9.

6. Bale AE, Drum MA, Parry DM, Mulvihill JJ. Familial.Sotos syndrome (cerebral gigantism): craniofacial and psychological characteristics. Am J Med Genet 1985; 20: 613-24.

7. Kurotaki N, Imaizumi K, Harada N, et al. Haploinsufficiency of NSD1 causes Sotos syndrome. Nat Genet 2002; 30: 365-6.

8. Douglas J, Hanks S, Temple IK et al. NSD1 mutations are the major cause of Sotos syndrome and occur in some cases of Weaver syndrome but are rare in overgrowth phenotypes. Am J Hum Genet 2003; 72: $132-43$.

9. Türkmen $S$, Gillessen-Kaesbach $G$, Meinecke $P$, Albrecht B, Neumann LM, Hesse V, Palanduz S, Balg S, Majewski F, Fuchs S, Zschieschang P, Greiwe M, Mennicke K, Kreuz FR, Dehmel HJ, Rodeck B, Kunze $\mathrm{J}$, Tinschert S, Mundlos S, Horn D. Mutations in NSD1 are responsible for Sotos syndrome, but are not a frequent finding in other overgrowth phenotypes. Eur J Hum Genet. 2003; 11: 858-65.

10.Geneviève Baujat, Valérie Cormier-Daire. Sotos syndrome. Orphanet J Rare Dis. 2007; 2: 36

11.Büyuikgebiz A, Kinik E. Sotos syndrome presenting with epilepsy. Turkish J Ped 1990; 32: 59-63.

12.A. P. Callanan, P. Anand \& E. C. Sheehy. Blackwell Publishing, Sotos syndrome with hypodontia. International Journal of Paediatric Dentistry 2006; 16:143-6.

13. Cole TRP, Hughes HE. Sotos syndrome: A study of the diagnosticcriteria and natural history. J Med Genet 1994; 31: 20-32.

14.Gorlin RJ, Cohen MM, Hennekam RCM.Syndromes of theHead and Neck, 4th edn. Oxford: Oxford University Press; 2001. p. 399-427.

15. Hirai N1, Matsune K, Ohashi H. Craniofacial and oral features of Sotos syndrome: differences in patients with submicroscopic deletion and mutation of NSD1 gene. Am J Med Genet A. 2011;12: 2933-9.
16. Takano M1, Kasahara K, Ogawa C, Katada H, Sueishi K. A case of Sotos syndrome treated with distraction osteogenesis in maxilla and mandible. Bull Tokyo Dent Coll. 2012; 53: 75-82.

17.17- Mikiko Inokuchi,Jouji Nomura, Yoshihiko Mtsumura, Motoko Sekida, Toshiro Tagawa. Sotos syndrome with enamel hypoplasia: a case report . J Clin Pediatr Dent 2001; 25: 313-6.

18.18- Johanna Kotilainen,Pia Pohjola,Sinikka Pirinen,Sirpa Arte,Pekka Nieminen Premolar Hypodontia is a Common Feature in SotosSyndrome With a Mutation in the NSD1 Gene. Am J Med Genet Part A 2009; 149A: 240914.

Yazışma Adresi:

Güler Burcu SENIRKENTLi

Başkent Üniversitesi, Diş Hekimliği Fakültesi

Çocuk Diş Hekimliği AD

11. Sokak No:26 Bahçelievler, Çankaya, Ankara

Tel : +903122151336

Faks : +90312212 2962

E-Posta: gburcubostanci@yahoo.com 